\title{
Serious infection caused by group C streptococci
}

\author{
ATM GHONEIM AND E MARY COOKE \\ From the Department of Microbiology, The University of Leeds, Leeds LS2 9NL, UK
}

SUMMARY Group C streptococci commonly cause infection in animals but only occasionally give rise to severe infection in man. We report here three cases of serious human infection due to this organism and discuss its pathogenicity in relation to the clinical manifestations of the disease.

Group C streptococci are a common cause of infection in animals but there is little information about their overall importance as a cause of human infection. Hutchinson ${ }^{1}$ found that their occurrence was approximately one-sixth of that of group A streptococci and suggested that their isolation be considered to be of the same significance as that organism.

However, it is generally considered that serious infection, particularly bacteraemia, endocarditis, and meningitis, due to group $\mathrm{C}$ streptococci is rare.

Cherubin and $\mathrm{Neu}^{2}$ surveying 656 cases of infective endocarditis, found none due to group $\mathbf{C}$ streptococci. Mohr and co-workers, ${ }^{3}$ examining 150000 blood cultures, found eight patients with group C streptococcal infection. Meningitis ${ }^{4}$ and cellulitis $^{5}$ due to this organism have also been reported, and it has been demonstrated to be nephritogenic. ${ }^{6}$

At the General Infirmary at Leeds we had had no cases of bacteraemia or endocarditis due to group C streptococci for several years until three isolates were obtained from the blood cultures of three seriously ill patients during one week. One of the patients had meningitis, the other two endocarditis and persistent bacteraemia. Since human infection with group $\mathrm{C}$ streptococci has rarely been described, an account of the finding of a cluster of cases of septicaemia due to this organism may be of interest.

\section{Case reports}

Three patients presented with symptoms of severe infection due to group $\mathrm{C}$ streptococci during a period of one week in January 1979.

Received for publication 13 August 1979
PATIENT 1

A 66-year-old man, a shopkeeper, was well until one week before admission. He then developed back pain severe enough to disturb sleep. This progressed to difficulty in walking, ataxia, and shaking.

On the day of admission he was found to be confused, groaning, and irritable. His temperature was $39.0^{\circ} \mathrm{C}$. His lungs were clear, there were no cardiac murmurs, and the abdomen was normal. There was a flexor response to pain and neck stiffness, and bilateral papilloedema was present. A computed tomographic scan showed no focal lesion and no hydrocephalus. Skull and spine $x$-rays showed no evidence of a subdural collection of pus. An exploratory burr hole was made and ventricular aspiration was performed. The cerebrospinal fluid contained $520 \times 10^{6} / 1$ white blood cells, mainly polymorphonuclear leucocytes, and $10 \times 10^{6} / 1$ red blood cells. Large numbers of Gram-positive cocci in chains were seen in the stained smear. No acid-fast bacilli were detected. The CSF glucose content was $4.6 \mathrm{mmol} / \mathrm{l}$ (blood $6.6 \mathrm{mmol} / \mathrm{l}$ ) and the protein was $0.71 \mathrm{~g} / \mathrm{l}$. The CSF and six blood cultures collected at the time of admission yielded beta-haemolytic streptococci of Lancefield group C. The organism was sensitive to penicillin, ampicillin, chloramphenicol, and cotrimoxazole and resistant to gentamicin and sulphonamides.

Chemotherapy was started immediately with benzyl penicillin, $1.2 \mathrm{~g}$ intravenously 2 -hourly, in addition to dexamethasone. Two days after admission his condition improved and he became apyrexial . At the height of his illness the SGOT levels reached 120 units/l but returned to normal levels within a week of treatment.

The patient kept four dogs which had been ill with diarrhoea and skin infection three weeks before he was admitted to hospital. The possibility that he was infected from his dogs led us to investigate 188 
faeces from the dogs but group C streptococci were not isolated.

\section{PATIENT 2}

An 81-year-old retired businessman was admitted to hospital because of severe retrosternal chest pain, lethargy, and malaise. He had been treated for three days with oral ampicillin for a chest infection.

On the day of admission he was pyrexial $\left(38 \cdot 2^{\circ} \mathrm{C}\right)$ and mildly confused. There were basal and right midzone crepitations. The patient had chronic rheumatic heart disease, and mitral and aortic systolic murmurs were present. Blood cultures were sterile.

Oral ampicillin was continued, and while on treatment the patient became apyrexial and his general condition improved. However, vague abdominal pain and anorexia continued. Three days after oral ampicillin had been discontinued, his temperature rose to $39 \cdot 2^{\circ} \mathrm{C}$. He then became jaundiced and confused. At that time the diagnosis of infective endocarditis was provisionally made. Several blood cultures were again taken and the patient was given benzyl penicillin, $0.6 \mathrm{~g}$ 4-hourly intravenously, in addition to gentamicin, $60 \mathrm{mg}$ 12-hourly intravenously. All the blood cultures yielded a Gram-positive coccus, later identified as a group $\mathrm{C}$ streptococcus. The minimal inhibitory concentrations (MIC) were: penicillin $0.06 \mathrm{mg} / \mathrm{l}$, ampicillin $0.12 \mathrm{mg} / \mathrm{l}$, cloxacillin $0.5 \mathrm{mg} / \mathrm{l}$, gentamicin $8.0 \mathrm{mg} / \mathrm{l}$, cephalothin $0.25 \mathrm{mg} / \mathrm{l}$, and clindamycin $1.0 \mathrm{mg} / \mathrm{l}$. The bactericidal levels of the serum were at dilutions of $1: 128$ or $1: 256$. The dose of gentamicin was adjusted daily to maintain satisfactory serum levels. The patient was treated with penicillin and gentamicin for 10 days, penicillin alone for two weeks, and subsequently with oral amoxycillin, $1 \mathrm{~g}$ 6-hourly for two weeks. Adequate serum bactericidal levels were maintained throughout.

Early in the illness the patient developed atrial fibrillation, the serum bilirubin rose to $67 \mathrm{mmol} / \mathrm{l}$, and the SGOT rose to 120 units/l. During treatment the serum bilirubin and SGOT showed a marked decrease but never returned to normal. The SGOT remained at 40 units/l. The abdominal ultrasound scan showed no focal abnormalities in the liver and no evidence of abdominal suppuration. However, a small gallbladder containing calculi was noted. Repeated blood cultures were sterile.

After four weeks of treatment the patient improved and was discharged from hospital. However, in spite of the successful control of infection, his condition continued to deteriorate and he died three months later.

PATIENT 3

A 72-year-old woman with 20 years' history of hiatus hernia was admitted from Casualty with a two-day history of melaena. Her temperature, haemoglobin, full blood count, blood urea, and electrolytes were normal. Endoscopy was performed and she was found to have a linear ulcer of the oesophagus which had recently been bleeding.

After endoscopy she became pyrexial $\left(38.2^{\circ} \mathrm{C}\right)$, tachypnoeic, and slightly confused. The pulse rate was $120 / \mathrm{min}$ and the blood pressure $110 / 80 \mathrm{mmHg}$. A diagnosis of right lower lobe pneumonia was made.

Sputum and blood cultures were collected. She was treated initially with ampicillin, $500 \mathrm{mg}$ 6-hourly intramuscularly, and subsequently with erythromycin, $500 \mathrm{mg} 8$-hourly orally, for two weeks. On the day following the development of pneumonia, she went into atrial fibrillation and was digitalised. She also developed a deep venous thrombosis of the left leg. From the one set of blood cultures initially received beta haemolytic streptococci group $\mathrm{C}$ were isolated. Later blood cultures were sterile. Repeat endoscopy after two weeks showed that the ulcer was almost healed, and biopsies taken from the ulcer and stomach were normal. Two weeks after admission the patient was discharged to a nursing home.

During the following four weeks she suffered from anorexia and vomiting and became pyrexial $\left(38.5^{\circ} \mathrm{C}\right)$. She was readmitted. On examination her lungs were clear, and a full blood count was normal. Repeated blood cultures were taken and the early cultures were sterile. However, 10 days after her second admission, two sets of blood cultures yielded a growth of beta haemolytic streptococci of group C. The source of the group $C$ streptococcal infection was considered to be either the respiratory tract or the gall bladder.

The patient was initially treated with cephazolin which was changed after the isolation of the organism to ampicillin and gentamicin for two weeks, followed by ampicillin alone for a third week. Cholecystectomy was performed after one week of chemotherapy and the diagnosis of active cholecystitis was confirmed. The patient continued to improve, and repeated blood cultures were sterile.

The patient kept a dog which was said to be healthy.

\section{Discussion}

Group C haemolytic streptococci are divided into four subgroups: Strep. equi, Strep. zooepidemicus, Strep. equisimilis, and Strep. dysgalactiae on the basis of differences in a few biochemical tests.? Sorbitol fermentation is more common in animal strains. However, the typing system of group $\mathrm{C}$ is rudimentary, and this is a cause of difficulty in 
conducting any epidemiological study of outbreaks caused by these organisms. All the isolates we obtained were confirmed by the Streptococcus Reference Laboratory, Colindale, to belong to group C streptococci and to subgroup zooepidemicus, and all the strains were biochemically identical. Strep. zooepidemicus is primarily an animal pathogen. The first patient may in fact have become infected from his dogs. Unfortunately, however, we failed to isolate similar organisms from these animals. The second patient gave no history of recent contact with animals, but he did own a factory where hides were handled. The third patient also kept a dog.

Both patients 1 and 3 had cholecystitis. There are no previously reported cases where group $C$ streptococci have been implicated in acute or chronic cholecystitis. In these two patients the illness started as an acute respiratory tract infection, and it is possible that it proceeded to endocarditis with the gall bladder infection as an accompanying but unrelated pathology.

Mohr and co-workers ${ }^{4}$ noticed an abnormally high SGOT level in a patient with meningitis caused by Strep. zooepidemicus and also in two patients with bacteraemia due to this organism. ${ }^{3}$ In our patients two had high SGOT levels. The changes were transient, and the levels returned to normal within a short period. In experimental pneumococcal infection in mice, Dick and Gemmel $^{8}$ have shown that transaminase levels increase markedly. The elevated enzyme activity was thought to indicate general cytotoxicity caused by the pneumococci, and there was experimental evidence to suggest that these changes were due to toxaemia rather than the mere presence of intact bacteria in blood. However, not a great deal is known about toxin production by group C streptococci. It is known that some strains of group $C$ and $G$ share with group $A$ the property of producing destructive extracellular enzymes, ${ }^{9}$ and that, at least in one outbreak, group $\mathrm{C}$ streptococci were associated with glomerulonephritis. ${ }^{6}$

With the increasing utilisation of serological grouping of haemolytic streptococci recognition of the role of non group A streptococci is likely to increase. It is important that the potential of these organisms to cause serious human disease is recognised.

Following this cluster of cases of septicaemia due to group $\mathrm{C}$ streptococci, no further cases have been noted during a six-month period. Beta haemolytic streptococci from other sites did not show any relative increase in the rate of isolation of group $\mathrm{C}$ streptococci which forms only $5 \%$ of the isolates in this hospital.

We thank Dr G Colman for confirmation of the grouping and for biochemical typing of the isolates, and Mr R M Gibson, Dr W Whittaker, and Dr A T R Axon for permission to report these cases.

\section{References}

${ }^{1}$ Hutchinson R I. Pathogenicity of group C (Lancefield) haemolytic streptococcus. Brit Med J 1946; 2 : 575-576.

${ }^{2}$ Cherubin C E, Neu H C. Infective endocarditis at the Presbyterian Hospital in New York City from 1938-1967. Am J Med 1971; 51: 83-96.

${ }^{3}$ Mohr D N, Feist D J, Washington J A, II, Hermans P E. Infections due to group C streptococci in man. Amer J Med 1979; 66: 450-456.

${ }^{4}$ Mohr D N, Feist D J, Washington J A, II, Hermans P E. Meningitis due to group $\mathrm{C}$ streptococci in an adult. Mayo Clin Proc 1978; 53: 529-532.

${ }^{5}$ Portnoy B, Reitler R. Cellulitis due to a haemolytic streptococcus type C. Lancet 1944; 2: 597-598.

${ }^{6}$ Duca E, Teodorovici G, Radu C, et al. A new nephritogenic streptococcus. J Hyg (Camb) 1969; 67: 691-698.

'Duma R J, Weinberg A N, Medrek T F, Kunz L J. Streptococcal infections: a bacteriologic and clinical study of streptococcal bacteremia. Medicine (Baltimore) 1969; 48: 87-127.

${ }^{8}$ Dick T B, Gemmell C G. The pathogenesis of pneumococcal infection in mice. $J$ Med Microbiol 1971; 4: 153-163.

${ }^{9}$ Feingold D S, Stagg N L, Kunz L J. Extra respiratory streptococcal infections. Importance of the various serologic groups. New Engl J Med 1966; 275: 356-361.

Requests for reprints to: Professor E Mary Cooke, Department of Microbiology, School of Medicine, The University of Leeds, Leeds LS2 9NL, UK. 